\title{
Will Mary Jane Leave You Heartbroken? Marijuana Use and Risk of Takotsubo Cardiomyopathy
}

\author{
Alexandra M. Sanchez ${ }^{1}$, Susie Sennhauser ${ }^{2}$, Matthew R. Lozier ${ }^{1}$, Joshua M. Purow ${ }^{3}$
}

1. Internal Medicine, Holy Cross Hospital/ University of Miami, Fort Lauderdale, USA 2. Cardiology, Mayo Clinic Jacksonville, Jacksonville, USA 3. Cardiology, Jim Moran Heart and Vascular Research Institute at Holy Cross Hospital, Fort Lauderdale, USA

Corresponding author: Alexandra M. Sanchez, ams712@med.miami.edu

\begin{abstract}
Takotsubo cardiomyopathy (TTC) is prevalent in $2 \%$ of patients who present with symptoms suggestive of acute myocardial infarction. It may be triggered by stressful events, resulting in catecholamine surges, myocardial stunning, and disturbances in contractility. TTC in males has been associated with marijuana use and leads to a fivefold increased risk of cardiac events. Marijuana is thought to generate a similar surge in catecholamines leading to tachycardia and elevation of both systolic and diastolic blood pressure. The question remains whether this catecholamine surge is sufficient enough to cause TTC. It is apparent a correlation between marijuana use and TTC may exist. Exogenous cannabinoid stimulation may lead to myocardial stunning via stimulation seen with hypercatecholaminergic states. Understanding the risk factors involved and increasing awareness of cardiovascular complications related to cannabinoid substances becomes more relevant as its use is increasing both recreationally and medically.
\end{abstract}

We present a case of a 50 year-old African-American male with hypertension and regular marijuana use who presented with chest pain radiating to the back. Due to abnormal electrocardiogram and positive cardiac biomarkers concerning for acute coronary syndrome, the patient underwent subsequent coronary angiography that showed no significant coronary obstruction; however, left ventriculogram showed the characteristic apical ballooning of TTC. Our case highlights the pathophysiological mechanism suspected to trigger TTC.

Received 10/10/2019 Review began 10/18/2019 Review ended 10/22/2019 Published 10/24/2019

○ Copyright 2019 Sanchez et al. This is an open access article distributed under the terms of the Creative Commons Attribution License CC-BY 3.0., which permits unrestricted use, distribution, and reproduction in any medium, provided the original author and source are credited.
Categories: Cardiology, Internal Medicine, Other

Keywords: takotsubo, cardiomyopathy, marijuana, catecholamines

\section{Introduction}

Takotsubo cardiomyopathy (TTC), also known as left ventricular apical ballooning syndrome or stress induced cardiomyopathy, is characterized by acute reversible left ventricular dysfunction in the absence of significant coronary artery disease (CAD) [1]. This cardiac condition, which may be triggered by stressful events, results in catecholamine surges and subsequent myocardial stunning presenting as transient disturbances in contractility [2-3]. Marijuana use generates a chemically similar surge in catecholamines leading to tachycardia and elevation of both systolic and diastolic blood pressure; however, it has yet to be determined whether this catecholamine surge is sufficient to cause TTC [1-3].

\section{Case Presentation}

A 50-year-old African-American male with regular marijuana use and a history of hypertension and hyperlipidemia presented with acute onset, retrosternal chest pain radiating to the back. Blood pressure upon admission was markedly elevated at 217/136 millimeters of Mercury (mmHg) with new dynamic electrocardiogram (ECG) abnormalities noted in the inferior leads [Figure ]. Serial troponin levels were obtained rising and peaking at 31.3 nanograms per deciliter (ng/dL) (normal range: $0-0.045$ ) with positive creatinine kinase-myoglobulin (CK-MB) index. Emergent cardiac computer tomographic angiographic (CCTA) imaging was obtained. Images revealed mild non-obstructive CAD as well as a left ventricular ejection fraction (LVEF) of approximately $28 \%$ with global left ventricular hypokinesis and apical dyskinesis. No aortic dissection was noted. A presumptive diagnosis of TTC was made based on these CCTA findings [Figure 2]. Due to abnormal ECG [Figure 3] and positive cardiac biomarkers concerning for acute coronary syndrome (ACS), the patient underwent subsequent coronary angiography that showed no significant coronary obstruction [Videos 1-2]; however, left ventriculogram showed the characteristic apical ballooning of TTC [Video 3 ]. 


\section{Cureus}

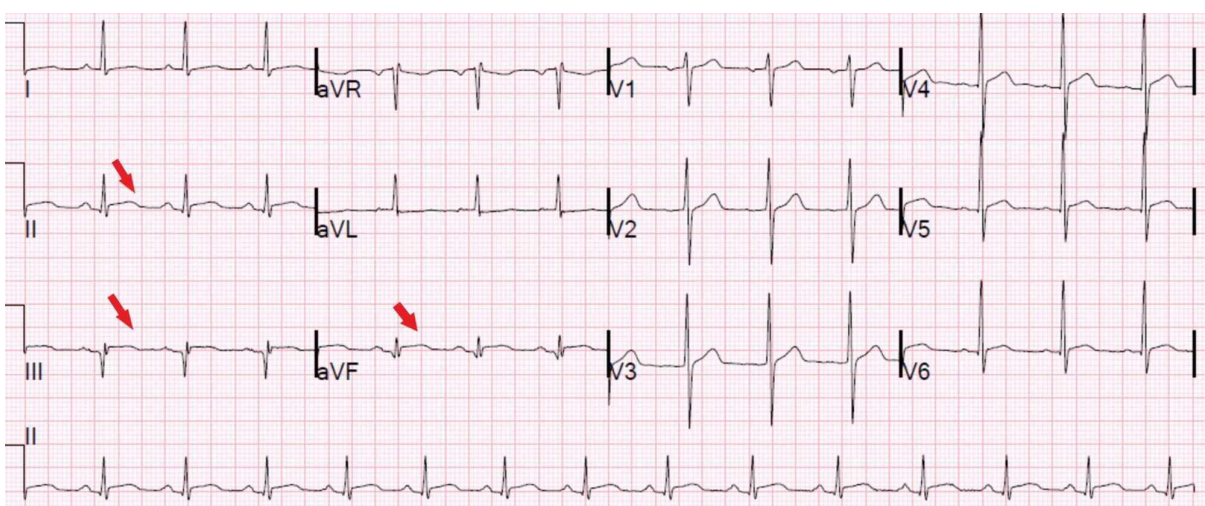

FIGURE 1: Initial electrocardiogram showing inferior ST elevations (red arrows), with troponins elevated at $1.270 \mathrm{ng} / \mathrm{dL}$

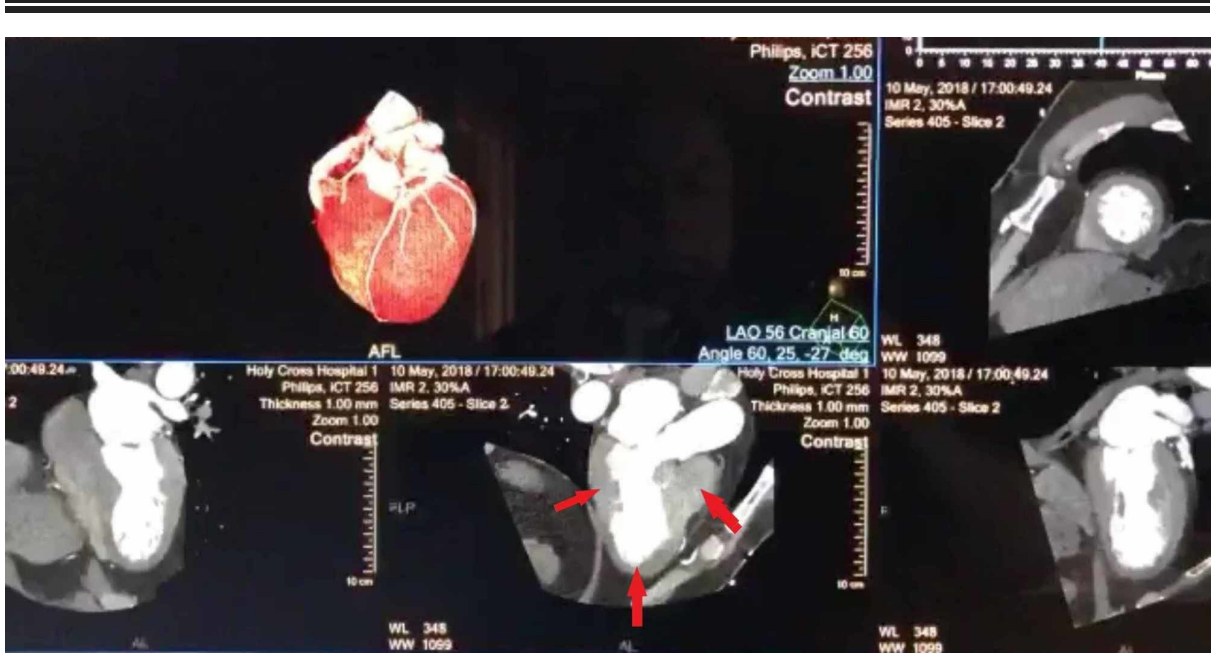

FIGURE 2: Coronary Computed Tomography Angiography with decreased perfusion in left ventricular apical segment and dyskinesia

The red arrows show a still image of a coronary computed tomography angiography demonstrating decreased perfusion to the left ventricular apical segment with an estimated ejection fraction of $28 \%$.

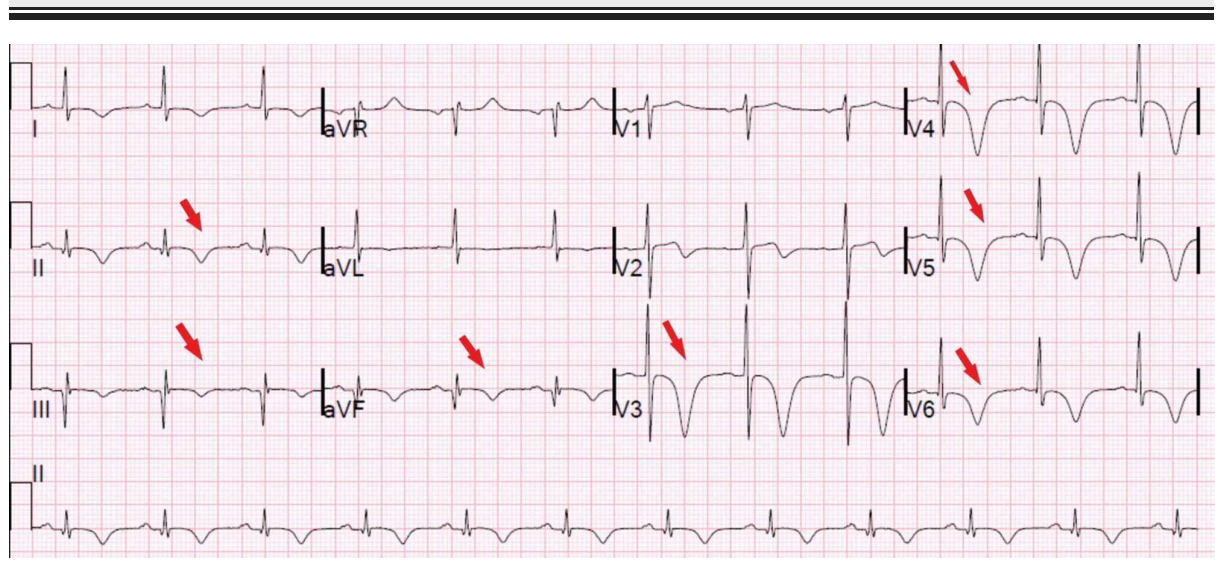

FIGURE 3: Electrocardiogram showing previous inferior infarct; anteroseptal and lateral ST-T wave abnormalities status post imaging with troponins peaked at $31.3 \mathrm{ng} / \mathrm{dL}$

The red arrows reflect post-ischemic T-wave inversions. 


\section{Cureus}

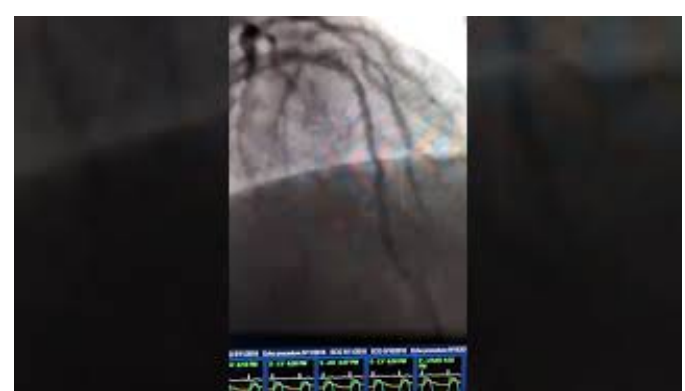

VIDEO 1: Coronary catheterization demonstrating no LAD obstructive disease

LAD: Left anterior descending artery

The video above shows diffuse mild and non-critical disease to the LAD.

View video here: https://youtu.be/G8giT-wTopo

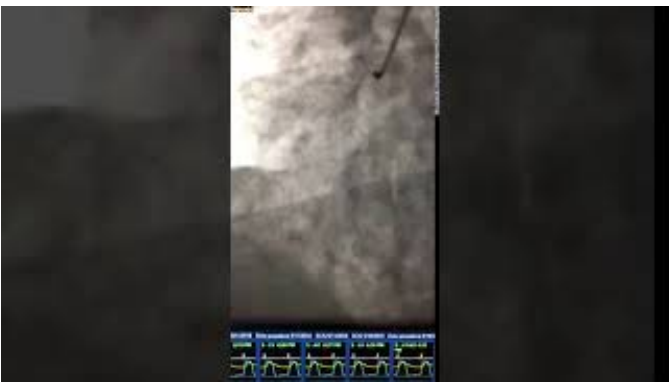

VIDEO 2: Coronary catheterization demonstrating no RCA obstructive disease

RCA: right coronary artery

The video above shows diffuse mild and non-critical disease to the RCA.

View video here: https://youtu.be/XYr4cd5yii8

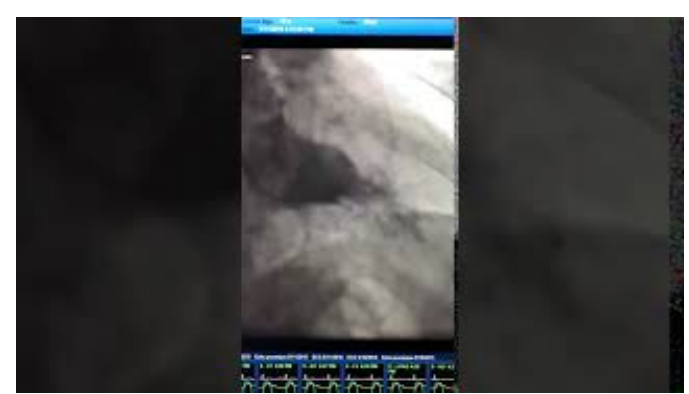

VIDEO 3: Left ventriculogram showing characteristic apical ballooning in takotsubo cardiomopathy

View video here: https://youtu.be/SvpTTwKAkwl

This case was presented as an abstract at the American College of Cardiology 68th Annual Scientific Session and Exposition Conference in March 2019

(https://www.sciencedirect.com/science/article/pii/S0735109719333170?via\%3Dihub).

\section{Discussion}


TTC accounts for approximately $2 \%$ of patients initially suspected of an ACS with roughly $90 \%$ occurring in women [1]. Some studies have found that women with TTC were noted to have an acute stressful event, while TTC in men was more commonly linked with active marijuana use [Abstract: Singh A, Agrawal S, Fegley M, Manda Y, Nanda S, Shirani J. Marijuana (Cannabis) Use is an Independent Predictor of Stress Cardiomyopathy in Younger Men. American Heart Association Scientific Sessions; November 2016]. The diagnosis should be considered in the differential of patients with dyspnea or chest pain in the setting of active marijuana use with symptoms mimicking acute myocardial ischemia (MI) [Abstract: Singh, November 2016]. Typically, coronary angiography shows no significant obstructive CAD; however, it is important to note that the risk of an acute MI increases nearly fivefold within an hour of cannabis exposure [2-4]. A definite link between marijuana use and a non-ischemic cardiomyopathy is difficult. As in this case, patients often have multiple factors that may contribute to the event, but marijuana use must be considered. Consequently, in such cases, a comprehensive history must be obtained including substance use.

The endocannabinoid system (ECS), composed of the cannabinoid receptors types 1 and 2 (CB1 and CB2) for marijuana's psychoactive ingredient $\Delta 9$ tetrahydrocannabinol ( $\triangle 9$-THC), is an important mediator between the hypothalamic-pituitary-adrenocortical (HPA) axis and stressful conditions [5-6]. Stress is recognized as an adaptive response to stressful stimuli, which activates the HPA axis and the sympathetic adrenergic system. It has been observed that the apex contains the highest $\beta$-adrenergic receptors ( $\beta A R s$ ) and lowest sympathetic nerve density [5]. The presence of ventricular $\beta$ AR gradient results in increased apical responsiveness to catecholamines, mainly epinephrine, which at high levels can have negative inotropic impact through the $\beta 2 A R 6$. These observations support the hypothesis that regional differences in $\beta 2 A R$ could explain the myocardial response to increased catecholamine circulation seen in TTC. Similarly, cannabinoid receptors (CB-1 receptors) are present in human cardiac muscle, allowing for cannabinoids to impact myocardial function [7]. It has been shown that endocannabinoids and THC elicit CB-1 receptormediated bradycardia, hypotension, and decreased cardiac contractility [8-9]. While the exact mechanism is still not fully understood; it is hypothesized that 'classical' and endothelial cannabinoid receptors prompt the release of nitric oxide resulting in a vasodilatory effect as well as inhibition of the peripheral nervous system and activation of the sympathetic nervous system [10-11].

Takotsubo cardiomyopathy has often been associated with hypercatecholaminergic states. A recent study showed that patients with TTC had catecholamine levels that were 2 to 3 times greater than patients with classic MI's, resulting in microvascular spasm and myocardial stunning likely secondary to beta-receptor mediated sympathetic stimuli [3,12-14]. Regarding the role of marijuana in TTC, it has been theorized that the endocannabinoid system may also cause physiologic stress as illustrated above, leading to cardiomyopathy.

Given the similarity in the pathophysiology of TTC and the mechanism of action of cannabis, it is important to further investigate the potential relationship between marijuana use and stress cardiomyopathy. This becomes even more relevant as the use of cannabis and cannabinoid substances increase both recreationally and pharmaceutically. As seen with endocannabinoid stimulation, a similar mechanism could apply to exogenous cannabinoids such as marijuana. Acute use is associated with tachycardia, while chronic use is linked with hypotension and bradycardia [15-16].

\section{Conclusions}

A true pathophysiologic explanation for TTC remains unclear; however it is apparent that it is not a homogeneous process. Through mechanisms discussed above, a strong correlation between marijuana use and TTC is suspected. This may indicate that exogenous cannabinoid stimulation may lead to myocardial stunning via more intense stimulation. Due to the fact that recreational and medical use of cannabis has sharply increased in the recent years, further research is warranted. It is necessary to increase awareness regarding the increased risk of cardiovascular complications associated with cannabis use.

\section{Additional Information}

\section{Disclosures}

Human subjects: Consent was obtained by all participants in this study. Conflicts of interest: In compliance with the ICMJE uniform disclosure form, all authors declare the following: Payment/services info: All authors have declared that no financial support was received from any organization for the submitted work. Financial relationships: All authors have declared that they have no financial relationships at present or within the previous three years with any organizations that might have an interest in the submitted work. Other relationships: All authors have declared that there are no other relationships or activities that could appear to have influenced the submitted work.

\section{References}

1. Komamura K, Fukui M, Iwasaku T, Hirotani S, Masuyama T: Takotsubo cardiomyopathy: Pathophysiology, diagnosis and treatment. World J Cardiol. 2014, 6:602-609. 10.4330/wjc.v6.i7.602

2. Singh A, Saluja S, Kumar A, Agrawal S, Thind M, Nanda S, Shirani J: Cardiovascular complications of marijuana and related substances: A review. Cardiol Ther. 2018, 7:45-59. 10.1007/s40119-017-0102-X 
3. Lyon AR, Bossone E, Schneider B, et al.: Current state of knowledge on takotsubo syndrome: A position statement from the taskforce on takotsubo syndrome of the heart failure association of the european society of cardiology. Eur J Heart Fail. 2016, 18:8-27. 10.1002/ejhf.424

4. Wittstein IS, Thiemann DR, Lima JA, et al.: Neurohumoral features of myocardial stunning due to sudden emotional stress. N Engl J Med. 2005, 352:539-548. 10.1056/NEJMoa043046

5. Micale V, Drago F: Endocannabinoid system, stress and HPA axis. Eur J Pharmacol. 2018, 834:230-239. 10.1016/j.ejphar.2018.07.039

6. Kaschina E: Cannabinoid CB1/CB2 receptors in the heart: Expression, regulation, and function . Cannabinoids in Health and Disease. Meccariello R (ed): IntechOpen, London; 2016. 169-186. $10.5772 / 62822$

7. Nogi M, Fergusson D, Chiaco JM: Mid-ventricular variant takotsubo cardiomyopathy associated with cannabinoid hyperemesis syndrome: A case report. Hawaii J Med Public Health. 2014, 73:115-118.

8. Bonz A, Laser M, Küllmer S, et al.: Cannabinoids acting on CB1 receptors decrease contractile performance in human atrial muscle. J Cardiovasc Pharmacol. 2003, 41:657-664. 10.1097/00005344-200304000-00020

9. Lim SY, Davidson SM, Yellon DM, Smith CC: The cannabinoid CB1 receptor antagonist, rimonabant, protects against acute myocardial infarction. Basic Res Cardiol. 2009, 104:781-792. 10.1007/s00395-0090034-2

10. Mukhopadhyay P, Bátkai S, Rajesh M, et al.: Pharmacological inhibition of CB1 cannabinoid receptor7 protects against doxorubicin-induced cardiotoxicity. J Am Coll of Cardiol. 2007, 50:528-536. 10.1016/j.jacc.2007.03.057

11. Randall MD, Kendall DA, O'Sullivan S: The complexities of the cardiovascular actions of cannabinoids . Br J Pharmacol. 2004, 142:20-26. 10.1038/sj.bjp.0705725

12. Meigh K, Caja M, Sharon M, Tadros A, Dragan S, Henkel D, Minardi J: Takotsubo cardiomyopathy in the emergency department: A focus heart breaker. Clin Pract Cases Emerg Med. 2018, 5:158-162. 10.5811/cpcem.2018.2.37291

13. Akashi YJ, Nakazawa K, Sakakibara M, Miyake F, Sasaka K: Reversible left ventricular dysfunction: "takotsubo" cardiomyopathy related to catecholamine cardiotoxicity. J Electrocardiol. 2002, 36:351-356. 10.1054/jelc.2002.36277

14. Pacher P, Mukhopadhyay P, Mohanraj R, Godlewski G, Bátkai S, Kunos G: Modulation of the endocannabinoid system in cardiovascular disease: Therapeutic potential and limitations. Hypertension. 2008, 52:601-607. 10.1161/HYPERTENSIONAHA.105.063651

15. Bathina J, Weiss S, Weintraub WS: Understanding the pathophysiology of apical ballooning syndrome: A step closer. expert review of cardiovascular therapy. Expert Rev Cardiovasc Ther. 2015, 13:5-8. 10.1586/14779072.2014.980237

16. Goyal H, Awad HH, Ghali JK: Role of cannabis in cardiovascular disorders . J Thorac Dis. 2017, 9:2079-2092. 10.21037/jtd.2017.06.104 